\title{
Using ADDIE Model to appraise MOOC English for Non- Academic Staffs (ENAS) Designed for University Non- Academic Staffs amid the COVID 19 Outbreak
}

\author{
Kartika Nuswantara ${ }^{1}$, Banu Prasetyo ${ }^{1}$, Gita Widi Bhawika ${ }^{2}$, Ni Wayan Suarmini ${ }^{1}$ \\ ${ }^{1}$ Department of Development Study, Institut Teknologi Sepuluh Nopember (ITS) Surabaya. \\ tika@mku.its.ac.id \\ ${ }^{2}$ Department of MMT, Institut Teknologi Sepuluh Nopember (ITS) Surabaya
}

Received: 01/01/2021.

Reviewed: 26/03/2021

Published: $31 / 07 / 2021$

Copyright $\odot 2021$ by the authors (et al) and Jurnal Sosial Humaniora (JSH)

*This work is licensed under the Creative Commons Attribution International License (CC BY 4.0). http://creativecommons.org/licenses/by/4.0/ Open Access

\begin{abstract}
Subject Area: Pendidikan (Education)
Abstract

To help universities non-academic staffs maintain their productivity amid the COVID 19 outbreak, MOOC ENAS was developed. To guarantee the eligibility of the program, through this research, ADDIE model was employed to evaluate the course plan. Step 1 and 2 out of the whole 5 steps of ADDIE were used to describe qualitatively about the course design. Using an online questionnaire, the authors received 110 responses and were able to demonstrate that the design had the quality for a goodcourse design. This was led by the results of investigation on the participants' background correspond to the course plan including the description and objectives. It was figured out that the design was able to accommodate the participants' language learning demands. The course design facilitated students learning by serving their education background, their workplace origin, and their already existing language learning experience. However, the study was lacking in the generalizability. To serve this, further research is needed by adding quantitative data so that the results of the evaluation could be presented in numbers that were more accurate and elusive. Finally, in terms of design, the MOOC ENAS is quite accommodating to be further continued into development of course content, implementation, and evaluation as assigned in ADDIE Model.
\end{abstract}

Keywords: MOOC; ADDIE method; program evaluation; COVID 19; outbreak.

\section{Introduction/Background}

In response to schools' complete closure during COVID-19 pandemic, Indonesia Ministry of Education issued a Circular Letter No. 36962/MPK. A/HK/2020 to make process of teaching and learning persisting without breaking the protocols. Schools are kept open through remote teaching, and school administration is also maintained to give all school circles the best education services although done from homes. It is the works of education staffs who have managed the administration so that academic activities can keep progressing. At the same token, all universities over Indonesia simultaneously foster remote teaching to keep teaching and learning process progressing by abruptly providing the facilities and other necessary infrastructures (i.e., robust internet connection, LMS, and the like) to support online or remote teaching and learning. Problems hindered the success of remote teaching are solved subsequently. Say for 
example, problems to afford internet quota is mitigated by subsidizing free internet quotas for teachers and students (see. Circular Letter No. 821E.E1/SP/2020, issued by Indonesia Minister of Education and Culture) After 9 months staying at home, people are now able to develop some new adaptations. Students start to get accustomed with online learning and start to be able to manage their learning process. Parents who complained at the early implementation of online learning are now able to find strategies to cope with problems encountered in their children's learning. Moreover, their complaints have received feedback from IT and education specialists who have launched various programs or applications to assist children.

As now internet connection and other online learning facilities are becoming more manageable (Berliyanto \& B. Santoso, 2016), universities are getting more sturdy in pursuing a new learning mode named Emergency Remote Learning that was, by some researchers, defined as an online learning mode specifically designed under unexpected situation like today. Such a learning mode, according to Purushotham, Phil, \& Scholar (2020) and Schlesselman (2020), suffers to some issues of unreadiness. Yet, along with the persistent evaluation during the ongoing process, the remote teaching and learning is now becoming better developed. In the context of learning in universities, such learning mode has now become well adapted and developed so that both teachers and students can start getting used to this learning mode (Rahim, Ali, Ali, \& Fayyaz, 2020). Along with the adaptations in the process of teaching and learning, all the campus circles including the non-academic staffs simultaneously adopt and adjust to such mode. They divert the offline tasks subsequently into online. They serve and assist the processes, students, and academic staffs (i.e., lectures) online. In short, all university circles inevitably accomplish the routines online.

Thank to COVID-19 pandemics that have made online atmosphere in Indonesia universities become more attractive. Along with restrictions the whole university circles stay at home and make online activities gain their magnitude. This has enabled education specialists to make online learning likeable; therefore, remote teaching is not getting better apt to students. Unfortunately, this is available only for students' learning. In fact, all circles deserve receiving opportunity to continue learning, not to mention the academic staffs. Prior to pandemics, they receive training to enhance their professional capacity. There should be no reliable reasons for not providing opportunity to help them learning and enhancing their professional capacities. Moreover, in these recent times, universities are eager to seek international recognition and they are inevitably involved staffs to take active roles. However, the lack of language competency is mostly figured out as the constraint to achieve a desirable result supporting that internationalisation (Sutrisno, 2019). Due to this reason, the authors develop a course to accommodate the staffs' language learning that at the same time can facilitate staffs accomplishing their routines.

By making the staffs learning and working at once, the authors consider developing an MOOC system. One of the reasons for considering MOOC as the online learning system is due to its ability to serve comfort learning zones where the participants or learners can learn autonomously with more flexible time and place while continuing to work on their routines (Berliyanto \& B. Santoso, 2016; Ginting, Djiwandono, Woods, \& Lee, 2020; and Yin, 2016). This learning system becomes more attractive as implemented during the pandemics where new adaptations have been made in response to the physical 
distancing and other protocols propagated during the pandemic. Moreover, people start to get used to working remotely from the offices and they also start to be very well acquainted with working through the internet, as several researchers have also claim that MOOC is considered subtle to be offered to this sort of people (Balakrishnan, 2020; Purushotham et al., 2020; Rahim et al., 2020), the present study promotes MOOC to be used as the learning system accommodating the non- academic staffs learning process during their WFH. By specifying the course on language learning, the authors develop MOOC of English for Non-Academic Staffs (MOOC ENAS, henceforth). The major aim of the course is to enhance the staffs' English mastery to facilitate them enhance theory professionalism in their career in university which is currently pursuing internationalisation. This is also used to delineate the constraints encountered that is sourced from the missing capacities to cope with English Language (Sutrisno, 2019). For this purpose, the course is designed based on the idea to increase their vocabulary size so that by means of ample vocabulary inventories they can perform various tasks that need English language to accomplish (Mokhtar et al., 2010; and Webb, Sasao, \& Ballance, 2017).

\section{Why Using MOOC Learning System}

The rationale for choosing MOOC learning system to support the course is due to the facts brought by previous research revealing its merits in the way that MOOC can be open to a large number of participants; moreover, such a learning system foster the learning autonomy where students can learn in their own place and pace. The effectiveness of such a learning system is no longer daunting since it gains more popularity today. In Portugal, Agonács \& Matos (2019) provided MOOC language learning and conducted a research regarding to the implementation of MOOC from the participants' point of view. In doing so, they run a research based on two theoretical pillars, namely heutagogy and the Common European Framework of Reference for Languages: Learning, Teaching, Assessment. Then, they identified some learning activities that were perceived by learners as preferred activities for skill acquisition in a language MOOC learning environment. The other MOOC language learning was hosted in Malaysia (Amantha Kumar \& Al-Samarraie, 2019), and the results demonstrated that students' general perceptions of the MOOC were positive, as reported by the students that they gained additional knowledge, marks towards their Diploma and benefiting from the opportunity to create an online learning community. However, they were challenged by their language competency and awareness of MOOCs. Outcomes from this study might have offered some practical implications to educational decision-makers in Malaysia towards promoting the use of MOOCs among students. Another study was conducted by (Motzo \& Proudfoot, 2017) that attempted to evaluate their LMOOC to find the opportunities and the challenges that then they were linked to the findings of other similar research.

From related studies, it is subsumed that Language MOOC (LMOOC) is quite attractive. Then, there is an open opportunity that LMOOC specifically provided for non-academic staffs is still lacking. In fact, as a part of the academia, the staffs need to regain knowledge to upgrade their personal capacities that at the same time will improve their performances in accomplishing the administration tasks. Foreign 
Language Learning, particularly English language, is one of the capacities that is immediately required to help them performing administrations that recently cannot only be coped with their second language, Bahasa Indonesia. Due to this reason, the authors propose MOOC for English for Non-Academic Staffs (ENAS). This study is a part of the journey for developing the program, from surveying the learning demands to the development of desirable course material. This present study seeks the evidence if the design of the course has already developed based on the participants' learning needs. It is mandatory to provide participants with a learning program that suits their need to make learning motivating and enjoyable so that learning ends with successful attainment. Such a learning setting can help learners persistent to learn so that they will at the same stay productive.

In regard to finding out if the course developed has met participants' learning demands, using ADDIE model, the present study reviewed the program from the first to steps, analysis and design, as depicted in the following questions:

1. In the analysis stage (i.e ADDIE Model step I), how are the characteristics of the participants of the course?

2. How do they show their commitment to join the MOOC as the online system selected to accommodate their language learning?

3. In the design stage (i.e. ADDIE Model step II), how the MOOC English Language Learning program for Non-academic staffs has met the participants' learning demands,

\section{Methodology}

\section{Research Model}

Case study method of qualitative research methodology is used to frame out the research. It is aimed at making an appraisal or review on the English Language Learning Program Specified for Non-Academic Staffs of Universities that was made available online using MOOC system. The program has been designed and brought into a field trial from July 2020 to August 2020 (i.e. 8 weeks). By adopting ADDIE model (step 1 (analysis) and step II (design), the present study attempts to review the design of the course. The results of the appraisal or review informed the authors if the program has met participants' learning demands. The investigation begins from step 1, analysis, that was done to seek the characteristics of the participants and their responds toward MOOC as the online learning system then continued to the next step, step 2, namely design from which the investigation of the design was made based on the identified demands. Therefore, instead of involving all 5 steps in ADDIE model, the study stopped at the second step. This is a part of the flexibility of ADDIE model that make the authors adopt this model to review the course before it is launched to public use. Not only due to its flexibility, ADDIE model is also easily applicable, and systematic then it is suitable to be used to evaluate online or distance learning program (Durak \& Ataizi, 2016; and Gökkaya \& Güner, 2014). 
Figure 1. The Flow of ADDIE Method (full steps)

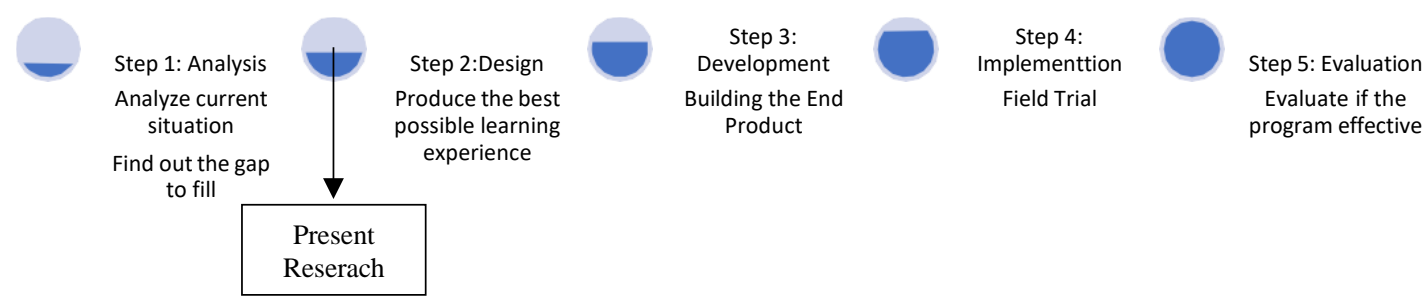

(source: https://waterbearlearning.com/addie-model-instructional-design/)

\section{Respondents}

There were 110 non-academic staffs who willingly joined the program as the participants in fieldtrial that was used as the format to first implement the program designed and they were all from different units, departments, and faculties in Institut Teknologi Sepuluh Nopember (ITS) Surabaya. They willingly responded the invitations from the authors to join the program after contacted directly through their mobile devices. Henceforth, those 110 participants become the population of the present study.

\section{Limitations}

The course was developed in the vicinity of the authors' institution (i.e. Institut Teknologi Sepuluh Nopember, Surabaya, Indonesia) so that the respondents involved to supply the needed data were all from the institution. In distribution of the instrument, the authors could not reach wider range of respondents due to a short period for collecting the data, After the participants completed the MOOC within 8 meetings, the authors had 2 weeks with them while they waited for the certificate of program completion (i.e the first two week of September 2020For future use the course should involve broader population range instead of the authors' institution, the eligibility of the course needs to be revisited by involving more participants with more varied characteristics. Then, the present study did not reveal evidence on how such characteristics could bring any impacts toward the quality of the program.

Another limitation of this research was in the steps in ADDIE model employed in this present study. Only two out five steps were employed involving the analysis of participants' learning needs and the design of the course. The rest of the steps were excluded in the present study due to a limited time. The present study only revealed a review on the characteristics of the participants and their respond to the MOOC system; additionally, a review was done to figure out if the programs were suit to the participants' learning demands. 


\section{Findings and Discussions}

\section{ADDIE Model Adaptations for MOOC ENAS}

This phase details the steps taken to overview the details of the program following the adaption of the ADDIE model that was taken as basis.

\section{Step 1: Analysis}

This step was done by distributing an online questionnaire that was written in the target respondent's language (i.e., Bahasa Indonesia). It was distributed in the first two week of September 2020. The questionnaire was used to determine the characteristics of the respondents, their language learning needs, and their preferable toward the online learning system. The descriptions of the participants would inform to the future users of the program so that the viability of the program could be maintained.

In the first place, it was identified from the responses that the respondents came from various background. The analysis of learners was conducted to inform the characteristics of participants that would be needed when the program was pursued. Characteristics like genders, experience in learning English, existing proficiency, education background, and kinds of job positions, workplace origin. According to Durak \& Ataizi (2016) it was important to conduct analysis regarding such characteristics of candidates who would use the online learning platform as this could make the course more productive and effective and increase learners' motivation. And the results demonstrated some facts including:

\section{A. Gender}

This was used to demonstrate that participants who were willing to submit the application to join the program involved both genders. 59.1 percent of the participants were female, and the rest (40.9 percent) were male staffs. Thus, in terms of genders, this informed that the program was susceptible to both genders; therefore, later in designing the program, it should be developed in such a way to consider possible effects of gender-related differences (Marley, 2007). It was claimed by Marley that genders had significant influence toward the success of learning using online mode. There were at least six factors in online learning whereas the success was affected by gender differences, including (1) motivation for enrolling, (2) learning style, (3) attitude toward and use of technology, (4) communication style, (5) level of support/sense of community, and (6) dropout or failure rate.

Figure 2. Respondents from different genders

\section{Genders}

110 responses

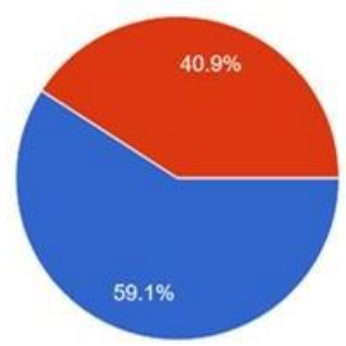




\section{B. Education Background}

From participants' education background (Figure 3), it was identified that the population was dominated by staffs with bachelor's degree (or undergraduate). As the holder of such degree, they were more amenable to learning activities involving High Order Thinking (HOT) skills. Therefore, course contents and activities should foster the skills of knowledge transfer, critical thinking and problem solving (Brookhart (2010) in Jaganathan \& Subramaniam, 2016). Regarding this characteristic, it was very possible that future use of the program should require staffs at least with bachelor's degree

\section{Figure 3. Participants Education Background}

\section{Education Background}

110 responses

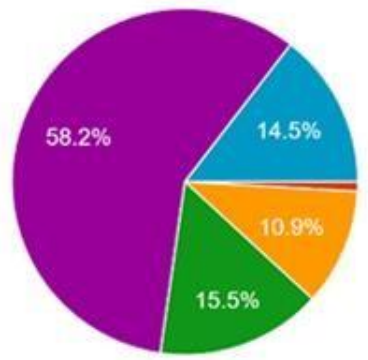

$\mathrm{SD} /$ sederajat

SMP/sederajat

SMA/sederajat

Diploma (D1/D2/D3)/sederajat

Sarjana (D4/S1)/sederajat

Pascasarjana (\$2/S3)/sederajat

\section{Positions in the Offices}

The positions occupied by each participant were asked in order to determine the origin of the staffs' workplace origin that would help the authors to determine desirable topics for the program materials. It would be much easier to for the participants to learn as the adult learners. According to (Sanger \& Gleason, 2020), adult learners' rich experience should also be tapped to facilitate their learning through problem-based teaching approach, which is preferred by adult learners who need to see relevance in what they are learning; therefore, by considering the positions of the staffs in their workplace, topics or themes could be selected from any issues around the participants' vicinities.

Figure 4. Participants' Workplace Origin (i.e.Position

Positions

110 responses

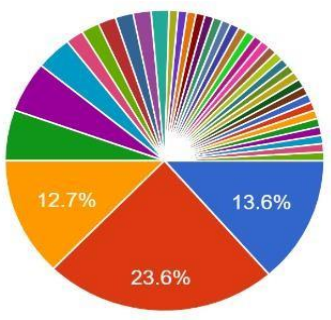

Administrasi Akademik

Administrasi Umum

Laboran

Teknisi Komputer

Pustakawan

Dosen

Pengelola Keuangan

Kasubbag TU

A $1 / 5 \nabla$ 
As depicted in Figure 4, participants were derived from different positions in the institutions, by it was dominated by general administration staffs then followed by academic administration staffs, and laborants. Thus, the most desirable topics that could be selected based on the positions of the staffs would be any topics regarding administration tasks. This finding led to figure out if the MOOC ENAS accommodated the participants' workplace origins.

\section{Prior Language Learning Experience}

It was not only the positions that were used to determine the most desirable topics or theme selected when developing the program materials. It should be kept in mind that the participants were adult learner who had gained wealth learning experience rather than just a blank slate (Sanger \& Gleason, 2020); therefore, including what they have already known to bridge the new knowledge would facilitate participants to perform tasks and solve immediate problems. Survey revealed that 55.5 percent staffs admitted that they have ever taken an English proficiency test and from the TOEFL scores they earned, the scores range quite wide, from 350 to 600 (see Figure 5). This determined the level of difficulty of the course contents. The contents should be managed equally so that both poles (lower and higher achiever) can really find learning effective. This evidence would support if the MOOC ENAS would be effective for participants with different proficiency levels. Unfortunately, as the aforementioned limitation, the present study exclude evaluation which was the last step in the ADDIE Model.

Figure 5. The span of participants' TOEFL scores

The highest score you have ever achieved 64 responses

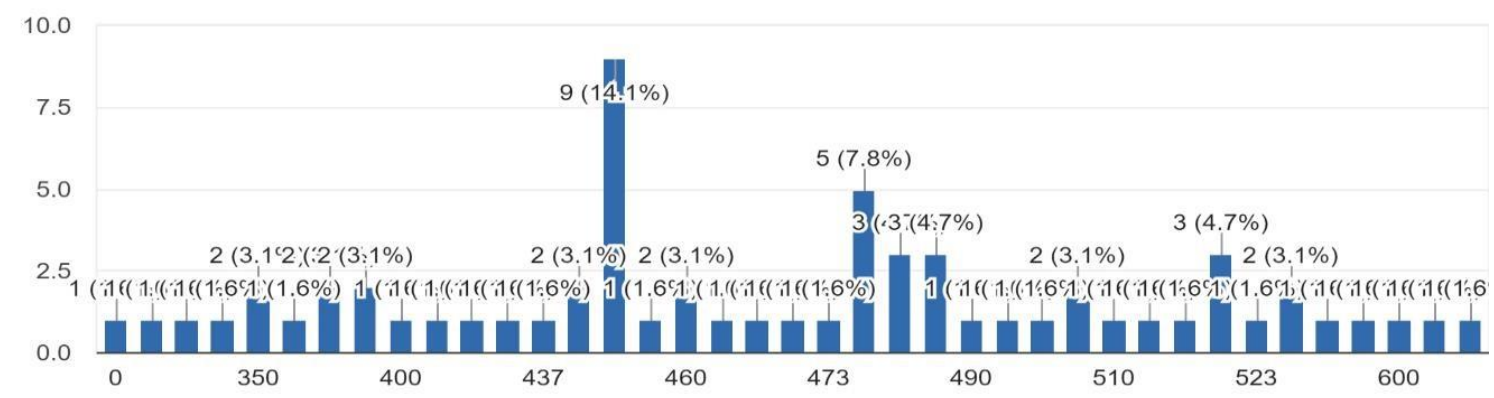

In regards to participants' respond toward the use of MOOC system to accommodate their online learning, there were 100 percent agree to use the MOOC learning system. They might realize that MOOC can still make them learn while they have to keep working the office routines. The flexibility of MOOC might be the reason for them to join the MMOC. 
JIKA MOOC dipilih sebagai sistem pembelajaran online untuk kursus ini, apakah Anda akan tetap berkomitmen untuk bergabung?

110 responses

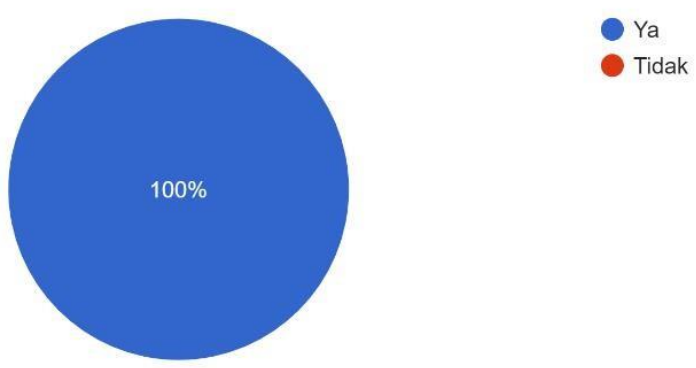

Finally, as it was figured out in step 1, it could be described that the MOOC ENAS ware participated by participants of both genders so that the materials or program should not need to consider any gendersensitive; it also attended by varied characteristics in terms of their workplace origin, education background and proficiency level. This early information would contribute further investigation especially when they were corresponded to the evaluation, or step 5 in ADDIE Model.

\title{
Step 2: Design
}

Information elicited from step 1 would help the authors to determine or value the design and figure out if the design of the MOOC ENAS has been in line with characteristics of the participant and then meeting the learning demands.

\section{A. Review of Course Description}

This section determined whether to course description and objective made by the authors have already meeting students' expectation, existing knowledge, and experience as well. Below are the excerpts presented ready for the appraisal.

\section{Excerpt 1: Course Description from the Syllabus of the program}

\begin{abstract}
The course is designed to help non-academic staffs of universities cope with English as needed in their workplace. Regarding to this, the course is aimed to provide instruction that enables staffs to accelerate their English competencies. The instruction emphasizes on reading comprehension, writing fluency, and vocabulary study using a variety of non-literary or informational texts encompassing a broad range of text structures, genres, and levels of complexity. Texts used for instruction focus on a wide range of content-area information that directly deal with common workplace issues. Staffs enrolled in the course will engage in interactive textbased discussion, question generation, and research opportunities. They will write in response to reading and cite evidence when answering text dependent questions orally and in writing. The course provides extensive opportunities for staffs to collaborate with their peers. Scaffolding is provided as necessary as staffs engage in reading and writing increasingly complex text and is removed as the reading and writing abilities of students improve over time.
\end{abstract}

Based on excerpt 1, several facts about the course were revealed. First, the course was developed based on the participants' field (as revealed in step 1) as depicted by the fact that the course designers had put workplace as the setting that would lead to selected kind of texts which linguistic features would have been familiar to the participants. This would advantage the participants as they could use their experience in the workplace to approach the comprehension to those selected texts. According to (Hutchinson, T. \& Waters, 
1987), this facilitates the use of content-based texts in language learning in which the learners are assisted to realize that by using such texts will be able to acquire knowledge with minimal hindrance. Then, the use of task-based activities accommodates the participants HOT skills that were assumed to have been existing in the participants whose education background was bachelor's degree and having experienced to take proficiency language test.

\section{B. Review of the Course Objective}

Course description was defined into four objectives distributed into four modules. Each module was designed to be completed after 2 weeks. Each of the objective is presented in the following excerpt

\section{Excerpt 2: Objective 1.}

To enhance staffs' active reading techniques to gain general ideas about the text and find specific piece of information in a text through speed reading techniques, such as skimming, scanning, word recognition, and independent reading.

Excerpt 2 displays the first learning objective that was subsequently followed by the other three objectives. It was explicitly stated on this objective that reading was used as the main skill to develop before went further to other skills. As it is claimed by Irwin (1991) in Samah \& Jusoff (2008) that in reading, there is as a transaction between the reader and the text in a specific context that will yield a creation of a new text in the mind of the reader; at the same token, reading describes "the ability to utilize the conceptual and linguistic knowledge a reader has and simultaneously the ability to increase its depth and scope by constructing more advanced mental structures" during which a person is engaged in the reading process. Thus, it is remarkably good that the course designers start with using reading as the main skill to be fostered before continuing to cope with other integrated skills.

\section{Excerpt 3: Objective 2.}

To help staffs developing vocabulary learning skills through:

a. linguistic and contextual clues to make meaning of unfamiliar vocabulary used in a variety of non-literary or informational texts,

b. using word parts (suffixes) and word association (synonyms \& antonyms)

\section{Excerpt 4: Objective 3.}

To improve staffs' ability to become active, thinking readers through applying critical reading and critical thinking skills. This involves analysis, interpretation, and evaluation. Each of the process helps staff to interact with the text in different ways: highlighting important points and examples, taking notes, testing answers to the questions, brainstorming, outlining, describing aspects of the text or argument, reflecting on reading and thinking, raising objections to the ideas or evidence presented.

\section{Excerpt 5: Objective 4}

To help staffs to develop their writing skills by integrating them with the technology competences commonly used in $21^{\text {st }}$ century skills through technical writing of email and social media. 
Excerpts 3,4, and 5 demonstrates how each objective is linked to the first objective. At the beginning of the course, participants were exposed to reading strategies used to comprehend specified texts, then it was followed by integrating their reading ability into other language skills and components. Say, excerpt 3 depicts how the second objective led participants to cope with vocabulary knowledge in receptive in which word meanings were derived from the context. At the same vein, reading was used to shape Higher Order Thinking (HOT) skills. The implementation of HOTS in classroom would be beneficial for both the participants whose characteristics were like the aforementioned to build conceptual variations on reading comprehension as well as the improvements of the skills in comprehending the academic reading texts (Jaganathan \& Subramaniam, 2016). As participants could sharp the HOT skills, their success of reading could lead the ability to show their understanding by re- expressing the content of the text, for example, by writing sentences or paragraphs in answering to the questions, picking the accurate options as the answer from a multiple-choice question or by summarizing the text (Greenall, S., \& Swan, 1986). This final rational is expressed by the final objective, whereas participants were exposed to writing skill development after they were able to develop better reading comprehension skills.

\section{Conclusion}

From the point of the description and objectives of the course, there was no explicit gender-sensitive statement, additionally as stated in the description that workplace became the main core leading to selected materials. Moreover, both in the description and objectives underpinned the implementation of task-based activities to elicit higher order thinking comprised in the strategies used to enhance reading skills and vocabulary enrichment. When linked to the participants' characteristics like their education background and varied proficiency, the activities were aptly designed. Therefore, in the context of this present study, ADDIE model that was employed until step 2 could reveal that MOOC ENAS, an English course for non-academic staffs working in universities, was determined to have a good design as it was developed congruently with the characteristics of the participants. The design that was seen from the course description and objectives demonstrated that the course would provide materials and learning activities suitable for workplace setting and then the implementation of content-based learning could nurture the participants' HOT skills, the skills that were assumed to have been existing in the bachelor's degree holder capacity. In other words, the course has been designed in line with suitable mastery level of the participants.

Recommendations are presented for further research that, firstly, quantitative data should be included in the research to support the qualitative description so that the result become more representing. Then, participants should involve staffs from other universities so that the outcome can serve more generalizable evidence, and the last, it is considered mandatory to continue the review by involving all 5 steps of ADDIE method. The present finding of the present study would describe the early stage of the quality of the program, by employing the other 3 steps, the information would be more holistic as it would be able to inform whether the program could be effective for participants with the characteristics as mentioned in step 1. All in all, from the first two steps in 
ADDIE model the program is eligible to be the foundation for the next steps, namely development, implementation, and evaluation stage.

\section{Acknowledgement}

This article is supported by the Local Funding Granted by The Directorate of Research and Community Services of Institut Teknologi Sepuluh Nopember (ITS) Surabaya under the contract No Nomor: 963/PKS/ITS/2020

\section{References}

Agonács, N., \& Matos, J. F. (2019). Understanding language MOOC learners: The issue of capability development. International Journal of Emerging Technologies in Learning, 14(11), 123-137. https://doi.org/10.3991/IJET.V14I11.10205

Amantha Kumar, J., \& Al-Samarraie, H. (2019). An Investigation of Novice Pre-University Students'Views towards MOOCs: The Case of Malaysia. Reference Librarian, 60(2), 134-147. https://doi.org/10.1080/02763877.2019.1572572

Balakrishnan, P. (2020). Education in the Age of COVID-19 : Educational Responses From FourSoutheast Asian Countries. ISEA, 48(3), 102-109.

Berliyanto, \& B. Santoso, H. (2016). Indonesian Perspective on Massive Open Online Courses: Opportunities and challenges. Journal of Educators Online.

Durak, G., \& Ataizi, M. (2016). The ABC's of Online Course Design According to Addie Model. Universal Journal of Educational Research, 4(9), 2084-2091.https://doi.org/10.13189/ujer.2016.040920

Ginting, D., Djiwandono, P. I., Woods, R., \& Lee, D. (2020). Is autonomous learning possible for asian students? The story of a mooc from Indonesia. Teaching English with Technology, 20(1),60-79.

Gökkaya, Z., \& Güner, N. (2014). ADDIE Model in Adult Education : Instructional Design Sample ofELearning. 5th International Future-Learning Conference on Innovations in Learning for the Future, 53(2011), 2011.

Greenall, S., \& Swan, M. (1986). Effective Reading: Reading Skills for Advanced Students. NewYork: Cambridge University Press.

Hutchinson, T. \& Waters, A. (1987). English for Specific Purposes: A learning-centered approach. Cambridge: Cambridge University Press.

Jaganathan, P., \& Subramaniam, I. (2016). Incorporating Higher Order Thinking Skills in Task-BasedLearning For Malaysian Undergraduates. International Journal of Contemporary Applied Sciences, 3(2), 274-288. Retrieved from www.ijcas.net

Marley, J. (2007). Gender differences and distance education: Major research findings and implications 
for LIS education. Journal of Education for Library and Information Science,48(1), 13-20.

Mokhtar, A. A., Rawian, R. M., Yahaya, M. F., Abdullah, A., Mansor, M., Osman, M. I., ... Mohamed, A. R. (2010). Vocabulary Knowledge of Adult ESL Learners. English LanguageTeaching, 3(1), 7180. https://doi.org/10.5539/elt.v3n1p71

Motzo, A., \& Proudfoot, A. (2017). MOOCs for language learning - opportunities and challenges: thecase of the Open University Italian Beginners' MOOCs. In Q. Kan \& S. Bax (Eds.), Beyond the language classroom: researching MOOCs and other innovations (pp. 85-97). https://doi.org/10.14705/rpnet.2017.mooc2016.673

Purushotham, S. L., Phil, M., \& Scholar, P. D. (2020). Online Learning and Its Effects on English Language Skills among Higher Education Students Amid the Covid-19 Lockdown. Languange in India, 20(September), 127-144.

Rahim, A., Ali, S., Ali, S., \& Fayyaz, H. (2020). Online Education During COVID-19: An Experienceof RIPHAH International University Faculty Of Health And Medical Science. Pakistan Armed Forces Medical Journal, 19(2), 506-513.

Samah, H. S. A. A., \& Jusoff, H. K. (2008). Teaching Comprehension Skills using Context -BasedTexts in Second Language Learning at Tertiary Level. International Education Studies, 1(4). https://doi.org/10.5539/ies.v1n4p118

Sanger, C. S., \& Gleason, N. W. (2020). Diversity ans Inclusion in Global Higher Education: Lessonsfrom Across Asis. In C. S. Sanger \& N. W. Gleason (Eds.), Palgrave Macmillan. https://doi.org/10.4324/9781315797885

Schlesselman, L. S. (2020). Perspective from a Teaching andLearning Center during EmergencyRemote Teaching. American Journal of Pharmaceutical Education, 84(8), 1-2. https://doi.org/10.5688/ajpe8142

Sutrisno, A. (2019). Internationalization of Indonesian Higher Education: Recent Initiatives and their Problems. International Higher Education, (97), 12-13.

Webb, S., Sasao, Y., \& Ballance, O. (2017). The updated Vocabulary Levels Test. ITL - InternationalJournal of Applied Linguistics, 168(1), 33-69. https://doi.org/10.1075/itl.168.1.02web 